\title{
Los sistemas de información digital: nuevas perspectivas
}

\section{Francisco Javier García Marco}

En este segundo número del año 1997 publicamos el resto de los trabajos presentados al II Encuentro sobre Sistemas de Información y Documentación que tuvo lugar en Zaragoza en febrero de este año. En él, un grupo de investigadores de toda España — acompañados por algunos colegas de otros paísesnos dedicamos a analizar los retos y perspectivas que los nuevos sistemas de información electrónica nos plantean como profesionales y académicos.

Este número está dedicado, sobre todo, a las perspectivas y soluciones. Se inicia con una reflexión de Javier Martínez Méndez sobre la formación de los profesionales de la información en los nuevos sistemas y documentos. Su trabajo apunta el surgimiento de toda una nueva serie de roles profesionales ligados a ellos, que incluye, entre otros, la figura del ingeniero de sistemas de información.

El segundo bloque de artículos está dedicado a la aplicación del concepto de sistema de información electrónico a la gestión de archivos y oficinas en las organizaciones. Arturo Camarero y Carlota Bustelo sugieren respectivamente una metodología para la implantación de sistemas de gestión electrónica en grandes entidades y unas estrategias prácticas para acometer la automatización del ciclo de vida de los documentos.

En la misma línea, Tomás Saorín conceptuzaliza las oficinas como un entorno de creación, archivo, recuperación y comunicación de documentos, y propone un paradigma 'documental' de la ofimática corporativa.

Estos trabajos son claves para comprender las nuevas demandas que las empresas, las administraciones y las entidades sin ánimo de lucro plantean a los profesionales de la información documental. La revolución digital ha mostrado

Scire. 3 : 2 (en.-jun. 1997) 9-10. 
de forma clara que archivo, representación, recuperación y comunicación son funciones inseparables que se deben abordar de forma conjunta. Como consecuencia, asistimos al despertar de unas necesidades hasta ahora dormidas a cuyo encuentro debemos salir con decisión.

Un tercer bloque de trabajos trata de las nuevas técnicas de recuperación de información que se han desarrollado para facilitar la explotación de los repositorios de información electrónica, cuya grave desestructuración dificulta la obtención de resultados precisos y exhaustivos. Jesús Tramullas explora las nuevas técnicas de 'minería de datos', orientadas a facilitar mediante procedimientos estadísticos y lógicos la recuperación de información en las 'bodegas' de bases de datos y documentos de todo tipo que han ido surgiendo en las organizaciones como resultado de la acumulación desordenada de información digital. Raúl Vaquero se ocupa del problema muy semejante que plantea la exponencial acumulación de información en la Internet y la solución más eficaz que hasta ahora se le ha encontrado: los motores de búsqueda.

Por fin, un cuarto grupo de artículos tiene que ver con aplicaciones concretas de las nuevas tecnologías a las labores tradicionales que se realizan en archivos, bibliotecas y centros de documentación. Javier Brun y Esperanza Velasco comparten con nosotros el proyecto de la biblioteca digital de Huesca. Ignacia Robledillo ofrece la experiencia de Chadwyck-Healey en la migración de sus servicios bibliográficos al nuevo medio digital, generando un nuevo y extraordinario valor añadido para los usuarios. Finalmente José Antonio Salvador nos muestra como los sistemas de información electrónicos pueden ser la respuesta a los procesos entrópicos con los que se enfrentan las grandes organizaciones, en concreto, la sanidad pública y los sistemas hospitalarios.

A través de los diferentes artículos, podemos ver como la revolución digital alcanza a todos los sectores sociales, aunque sólo sea indirectamente. Los sistemas de información electrónica plantean nuevos problemas, pero, sobre todo, ofrecen soluciones a las limitaciones de los servicios actuales y crean oportunidades absolutamente novedosas. Pero, en cualquier caso, nos guste o no, la revolución digital no tiene retorno, y está generando una nueva infraestructura tecnológica sobre la que, inevitablemente, los profesionales y científicos de la información del futuro inmediato tendrán que trabajar y desarrollar su carrera profesional.

Zaragoza, a 30 de diciembre de 1997. 